Research Paper

\title{
Low dose of Bisphenol A enhance the susceptibility of thyroid carcinoma stimulated by DHPN and iodine excess in F344 rats
}

\author{
Jing Zhang ${ }^{1,2, *}$, Xiaochen Zhang ${ }^{3, *}$, Yanan $\mathrm{Li}^{4}$, Zhenzhen Zhou ${ }^{5}$, Chuanlong Wu ${ }^{1}$, \\ Zhiyan Liu' ${ }^{6}$, Lanxiang Hao ${ }^{1,7}$, Shanshan Fan ${ }^{1}$, Fang Jiang ${ }^{1}$, Yan $\mathrm{Xie}^{1}$ and Ling Jiang ${ }^{1}$ \\ ${ }^{1}$ Department of Endocrinology, Qilu Hospital of Shandong University, Jinan 250012, China \\ ${ }^{2}$ Department of Hemodialysis, Heze Municipical Hospital, Heze 274000, China \\ ${ }^{3}$ Department of Nursing, Heze Medical College, Heze 274000, China \\ ${ }^{4}$ Department of Endocrinology, Laiwu City People's Hospital, Laiwu 271100, China \\ ${ }^{5}$ Department of Radiotherapy, Jinhua Municipal Central Hospital, Jinhua 321000, China \\ ${ }^{6}$ Department of Pathology, Qilu Hospital of Shandong University, Jinan 250012, China \\ ${ }^{7}$ Department of Endocrinology, Yancheng First People's Hospital, Yancheng 224001, China \\ * These authors have contributed equally to this work \\ Correspondence to: Ling Jiang, email: jiangling76@medmail.com.cn \\ Keywords: Bisphenol A, iodine excess, thyroid carcinoma, estrogen receptor $\alpha, P C N A$ \\ Received: April 02, $2016 \quad$ Accepted: June 02, $2017 \quad$ Published: July 22, 2017 \\ Copyright: Zhang et al. This is an open-access article distributed under the terms of the Creative Commons Attribution License 3.0 \\ (CC BY 3.0), which permits unrestricted use, distribution, and reproduction in any medium, provided the original author and source \\ are credited.
}

\section{ABSTRACT}

Thyroid carcinoma (TC) is the most common endocrine neoplasm. The risk of TC as a second primary malignancy (SPM) of breast cancer is significantly increased. Bisphenol A (BPA) is a widely contacted xenoestrogen and increases susceptibility to breast cancer through binding to estrogen receptor alpha (ER $\alpha$ ). However, the effect of BPA on thyroid carcinogenesis has not been fully demonstrated. This present study aimed to characterize the effects of BPA on the development of TC using a Fischer 344 (F344) rat model. In this study, we established a TC model using female F344 rats pretreated with N-Bis (2-hydroxypropyl) nitrosamine (DHPN) at a single dose of 2800 $\mathrm{mg} / \mathrm{kg}$ (the DA group) or without DHPN (the DN group), followed by stimulation with BPA at the level of $250 \mu \mathrm{g} / \mathrm{kg}$ (BPA250) or $1000 \mu \mathrm{g} / \mathrm{kg}$ (BPA1000) and a basic diet containing potassium iodine (KI, $1000 \mu \mathrm{g} / \mathrm{L}$ ) for 64 weeks. We demonstrated that the incidence of TC in the BPA250 + KI of DA groups reached the highest at $50 \%$, the incidence of thyroid hyperplasia lesions (including both tumors and focal hyperplasia lesions) in the BPA1000 + KI of DA groups reached $100 \%(P<0.05)$. ER $\alpha$ protein and immunochemistry expression was upregulated in the BPA-exposed groups and the immunochemistry scores were positively correlated with PCNA. Thus, the present results indicate that BPA could enhance the susceptibility to TC stimulated by DHPN and iodine excess. ERa is probably involved in the proliferation effect of BPA. BPA or KI alone could not increase TC incidence.

\section{INTRODUCTION}

$\mathrm{TC}$ is the most common malignant tumor in the endocrine system and is mainly categorized into papillary, follicular, medullary, and anaplastic TC. Papillary thyroid carcinoma (PTC) accounts for more than $80 \%$ of all the pathological types [1]. The risk factors for the morbidity of
TC include an excess and/or deficiency of iodine intake [2], radiation exposure [3], sex hormone, and environmental pollutants [4], among others. Tumorigenesis is due to the abnormality of gene alterations and regulations, which leads to unlimited cell proliferation [5]. For the thyroid, focal papillary hyperplasia and $\mathrm{C}$-cell proliferation are common types of thyroid proliferative lesions $[6,7]$. 
Table 1: Iodine intake and urine iodine concentration of rats

\begin{tabular}{lcccc}
\hline Group & $\mathbf{n}$ & Iodine intake $(\boldsymbol{\mu g} / \mathbf{d})$ & MUI $(\boldsymbol{\mu g} / \mathbf{L})$ & Average $\mathbf{U I C}(\boldsymbol{\mu g} / \mathbf{L})$ \\
\hline Control & 5 & 5.20 & 86.09 & $90.50 \pm 18.83$ \\
KI & 5 & 20.50 & $320.36^{* *}$ & $311.84 \pm 19.22^{* * *}$ \\
\hline
\end{tabular}

${ }^{* *} P<0.01$, compared to the control group. ${ }^{* * *} P<0.001$, compared to the control group.

MUI: median of urinary iodine; UIC: urinary iodine concentration.

Iodine excess usually occurs when the median urinary iodine (MUI) is more than $300 \mu \mathrm{g} / \mathrm{L}$ [8]. A clinical study showed that an excessive iodine state was seen in $66.99 \%$ of PTC patients, significantly higher than control group with a ratio of $19.93 \%$, which demonstrated an association between high MUI and thyroid malignancy [9]. A 5-year prospective epidemiological study showed 10 patients were identified and 13 new cases were diagnosed as TC in an excessive iodine intake area, while none was found in both deficient and normal iodine intake areas [6]. An increased incidence of PTC was also found in Hawaii and Iceland, which are both high iodine intake areas [10, 11]. DHPN is a drug with the ability to stimulate thyroid proliferation and convert into adenoma or carcinoma [12]. In animal researches, iodine excess has been reported to promote the proliferation of thyroid follicular cells and eventually result in TC if animals are pretreated with DHPN $[2,13]$. Nevertheless, the definite carcinogenesis effect of excess iodine is still controversial; more evidence is needed in vivo and in vitro.

$\mathrm{TC}$ is a hormone-dependent carcinoma $[14,15]$. The ratio of females to males is about 3 5:1. The risk of TC as an SPM of breast cancer is significantly increased and vice versa, suggesting the effect of estrogen could not be neglected [16]. Estrogen could stimulate cell proliferation via $\mathrm{ER} \alpha[17,18]$. In human TC tissue, elevated expression of ER $\alpha$ has also been reported, especially when coexisting with breast cancer [19, 20].

BPA, which is widely used to make epoxy resins and polycarbonate plastics, has weak estrogenic activity and belongs to the family of environmental endocrine disruptors (EEDs) [21, 22]. Animal research has shown that BPA can lead to precancerous lesions and carcinoma in the reproductive system and breasts [21, 23, 24]. The U.S. Environmental Protection Agency has defined a lowest observable adverse effect level (LOAEL) of $50 \mathrm{mg} / \mathrm{kg} / \mathrm{day}$ for BPA in rat research [25]. But recent studies found that BPA can create a biological effect below LOAEL [26-28]. T. j. Murray et al [26] treated rats with BPA from the fetal period at gradient concentrations of $2.5,25,250$, and $1000 \mu \mathrm{g} / \mathrm{kg} /$ day; the percentage of ductal hyperplasia in the mammary glands including carcinoma in situ (CIS) increased significantly, even at the lowest level of $2.5 \mu \mathrm{g} / \mathrm{kg} /$ day. BPA can bind to ER $\alpha$. The ER $\alpha$ inhibitor ICI182 780 can block the proliferation effect of BPA [28]. Evidence of BPA contributing to breast and reproductive tumors is sufficient, but the effects of BPA on TC development and ER $\alpha$ expression are largely unknown. Several studies have found that excess iodine was regarded to have a potential carcinogenesis effect on the thyroid. This present study aimed to observe the effect of BPA on TC development, with or without basic KI treatment. In our research, we speculate that BPA could promote thyroid proliferation and increase the susceptibility to TC on the basis of iodine excess. ER $\alpha$ may be correlated with the biological effect of BPA on thyroid carcinogenesis.

\section{RESULTS}

\section{Urinary iodine concentration of F344 rats}

As was shown in Figure 1, the rats were divided into several groups according to different treatments. To assess the iodine intake of rats, urinary iodine concentrations (UICs) in KI and the control of the DA groups were detected as 2 representative groups (the average daily water intake had no apparent difference among all the groups). The results showed the MUI in KI (320.36 $\mu \mathrm{g} / \mathrm{L})$ reached the standard of iodine excess recommended by WHO and was significantly higher than the control (86.09 $\mu \mathrm{g} / \mathrm{L})(P<0.01)$. The average UIC in KI $(311.84 \pm 19.22$ $\mu \mathrm{g} / \mathrm{L})$ was also significantly higher than in the control $(90.50 \pm 18.83 \mu \mathrm{g} / \mathrm{L})(P<0.001)$ (Table 1$)$.

\section{General condition and bodyweights of F344 rats}

To evaluate the effect of BPA on the rats' growth process, their mental state, hair growth, and bodyweight were observed.

In the DN groups, the rats survived well; no apparent differences in living stage and hair growth were noticed among the BPA250, BPA1000, and controls, even on the basis of KI. As for bodyweight, BPA-exposed groups tended to decrease compared to the controls, but showed no significance. In the DA groups, negative mental states and thin hair were widely observed, but BPA did not worsen the general condition. Also, no obvious bodyweight changes occurred among all of the DA groups. Particularly, bodyweight in the DA control group $(158.33 \pm 17.84 \mathrm{~g})$ was significantly lower than in the DN control group $(198.80 \pm 28.09 \mathrm{~g})(P<0.05)$ (Table 2). 
Table 2: Data of bodyweight, serum $\mathrm{FT}_{3}, \mathrm{FT}_{4}$, and TSH concentration of rats

\begin{tabular}{lcccccc}
\hline Group & & $\mathbf{N}$ & Bodyweight $(\mathbf{g})$ & $\mathbf{F T}_{\mathbf{3}}(\mathbf{p m o l} / \mathbf{L})$ & $\mathbf{F T}_{\mathbf{4}}(\mathbf{p m o l} / \mathbf{L})$ & $\mathbf{T S H}_{(\boldsymbol{\mu} \mathbf{I U} / \mathbf{m L})}$ \\
\hline DN & & & & & & \\
& Control & 10 & $198.80 \pm 28.09^{*}$ & $3.49 \pm 0.91$ & $17.99 \pm 2.70^{*}$ & $2.71(1.78,2.93)$ \\
& BPA250 & 7 & $156.33 \pm 7.55$ & $2.33 \pm 0.52$ & $20.18 \pm 6.00$ & $1.69(1.40,1.86)$ \\
& BPA1000 & 8 & $179.11 \pm 16.70$ & $3.48 \pm 1.36$ & $24.77 \pm 10.12^{*}$ & $1.72(1.56,2.22)$ \\
& BPA250 + KI & 9 & $160.27 \pm 17.37$ & $4.21 \pm 0.67$ & $20.42 \pm 3.08$ & $0.98(0.61,2.97)$ \\
& BPA1000 + KI & 10 & $158.44 \pm 34.54$ & $2.99 \pm 1.12$ & $18.68 \pm 6.09$ & $1.57(1.47,1.67)$ \\
& & & & & & \\
& Control & 8 & $158.33 \pm 17.84^{*}$ & $3.17 \pm 0.38$ & $18.37 \pm 3.28$ & $1.17(0.58,4.16)^{*}$ \\
& BPA250 & 9 & $158.00 \pm 21.12$ & $3.31 \pm 0.74$ & $21.26 \pm 4.09$ & $1.61(1.53,1.64)$ \\
& BPA1000 & 9 & $150.29 \pm 10.01$ & $2.85 \pm 0.41$ & $23.87 \pm 3.94$ & $2.13(1.58,2.68)$ \\
& BPA250 + KI & 10 & $156.42 \pm 17.43$ & $3.37 \pm 0.94$ & $20.70 \pm 2.18$ & $1.51(1.46,1.59)$ \\
& BPA1000 + KI & 10 & $162.50 \pm 10.13$ & $3.53 \pm 0.68$ & $18.44 \pm 3.27$ & $1.75(1.61,1.90)$ \\
& KI & 9 & $157.22 \pm 6.51$ & $3.08 \pm 1.06$ & $19.63 \pm 4.26$ & $1.56(1.48,5.96)^{*}$ \\
\hline
\end{tabular}

*Significant difference between the 2 groups at $P<0.05$.

\section{Effects of BPA and KI on the absolute and relative thyroid weights of $\mathrm{F344}$ rats}

To assess whether BPA and KI could affect thyroid weights, the absolute and relative thyroid weights were recorded.

In the $\mathrm{DN}$ groups, the absolute and relative thyroid weights had no significant differences among groups (Figure 2A and 2B). With the increasing dosages of BPA and the administration of KI, relative thyroid weights showed a trend to increase, but had no statistical significance.

In the DA groups, both absolute and relative thyroid weights showed statistical significances among all groups $(P<0.01)$ (Figure 2C and 2D). BPA250 or BPA1000 alone did not apparently increase both absolute and relative thyroid weights. While the KI group had the heaviest thyroid weights and showed significant differences compared to the control group (34.84 \pm 14.04 vs $16.87 \pm 2.34 \mathrm{mg}, P<0.001 ; 22.17$ \pm 9.06 vs $10.75 \pm 1.78 \mathrm{mg} / 100 \mathrm{~g}$ bodyweight, $P<0.001$ ). As for the BPA250 + KI and BPA1000 + KI groups, 3 samples had abnormally heavy thyroid weights, respectively, 235.0 $\mathrm{mg}$ in the BPA250 + KI group, and $347.2 \mathrm{mg}$ and $148.7 \mathrm{mg}$ in the BPA1000 + KI group. After being excluded from the statistical analysis, the absolute and relative thyroid weights in the BPA $250+\mathrm{KI}$ and BPA1000 + KI of the DA groups showed a weaker increase than the DA control group, but with no statistical significance.

\section{Effects of BPA and KI on incidence and pathological types of thyroid tumors}

After a 64-week exposure time, a total of 11 thyroid tumors were found in all rats, 1 in the DN groups and 10 in the DA groups.
In the $\mathrm{DN}$ groups, 1 tumor occurred in BPA1000 + KI (1/10), which was a typical PTC. No tumors occurred in BPA250 or BPA1000. Tumor incidence had no significant differences among all groups (Figure 3C).

In the DA groups, BPA250 + KI had the highest tumor incidence of $50 \%(5 / 10)$; all were PTC, with interstitial infiltration in 1 tumor. Furthermore, 2 tumors occurred in the BPA1000 + KI group (2/10), an anaplastic thyroid carcinoma (ATC) and a medullary thyroid carcinoma (MTC), respectively. In addition, a PTC occurred in the control (1/8), a PTC accompanied by obvious interstitial infiltration occurred in the BPA1000 group (1/9), and a benign adenoma occurred in the KI group (1/9). No neoplasm occurred in the BPA250 group (0/9) (Figure 3D). Among all of the DA groups, tumor incidence showed no apparent differences. Typical TC pathological structures are shown in Figure 3B.

\section{Effects of BPA and KI on incidence and pathological types of thyroid hyperplasia lesions}

In the present research, thyroid hyperplasia lesions were separated into 2 parts: thyroid tumors and focal hyperplasia lesions. Except for the thyroid tumors mentioned above, the numbers of thyroid focal hyperplasia lesions were also examined, including crowed cell arrangement, benign papillary hyperplasia, atypical papillary hyperplasia, and C-cell proliferation (Figure 3B). Particularly, atypical papillary hyperplasia and C-cell proliferation were respectively thought as precancerous lesions of PTC and MTC.

In the DN groups, the rate of thyroid focal papillary hyperplasia in BPA250 was a minimum of $14.29 \%(1 / 7)$ 
and in the BPA250 + KI group a maximum of $44.44 \%$ (4/9). No statistical significance was found among all DN groups (Figure 3C). In the DA groups, focal hyperplasia appeared most often in the BPA $1000+$ KI group, reaching $80 \%(8 / 10)$, followed by the KI group with a rate of $77.78 \%(7 / 9)$. BPA250 had the lowest rate at $22.22 \%$ (2/9). There also were no significant differences among all of the groups (Figure 3D). However, the total number of hyperplasia lesions (including both tumors and focal hyperplasia lesions) showed a significant difference among all of the DA groups $(P<0.05)$. Overall, 10/10 thyroids had a tumor or focal hyperplasia in BPA1000+ $\mathrm{KI}$, which was significantly higher than in the control $(4 / 8$, $P<0.05)$, followed by KI $(7 / 9)$ and BPA250 $+\mathrm{KI}(7 / 10)$ (Figure 3D). No statistical difference was found among all of the DN groups.

As for the pathological types, benign papillary hyperplasia and crowed cell arrangement happened in almost all of the groups with no clear regularity. In particular, 2 atypical papillary hyperplasia and $1 \mathrm{C}$-cell proliferation appeared in BPA1000 + KI of the DA groups, 1 atypical papillary hyperplasia happened in BPA250 + KI of the DA groups, and 1 atypical papillary hyperplasia and $1 \mathrm{C}$-cell proliferation occurred in KI of the DA groups.

\section{Effects of BPA and KI on the expression of PCNA}

As for KI alone, the immunochemistry score of PCNA in KI of the DA groups had a tendency to increase, although there was no significance (Figure 4B). The Western blotting detection in the control and KI of the DA groups confirmed this tendency $(P<0.05)$ (Figure 5A).

Considering BPA alone, in the DN groups, the PCNA immunochemistry expression in BPA1000 was the highest among the control, BPA250, and BPA1000 groups, although no statistical significance was found among the 3 groups (Figure 4A). Consistently, in the DA groups, BPA1000 had the highest PCNA expression among the corresponding 3 groups (Figure 4B). The Western blotting result in the control, BPA250, and BPA1000 groups was consistent with the trend (Figures 4D and 5B).

When combining KI and BPA together, in the DN groups, PCNA immunochemistry expression in BPA250+ $\mathrm{KI}$ and BPA1000 + KI did not show an apparent increase than the other subgroups (Figure 4A). In the DA groups, PCNA expression in BPA250 + KI was the highest among all of the DA groups, which was significantly higher than control $(P<0.05)$, followed by BPA1000 + KI. No

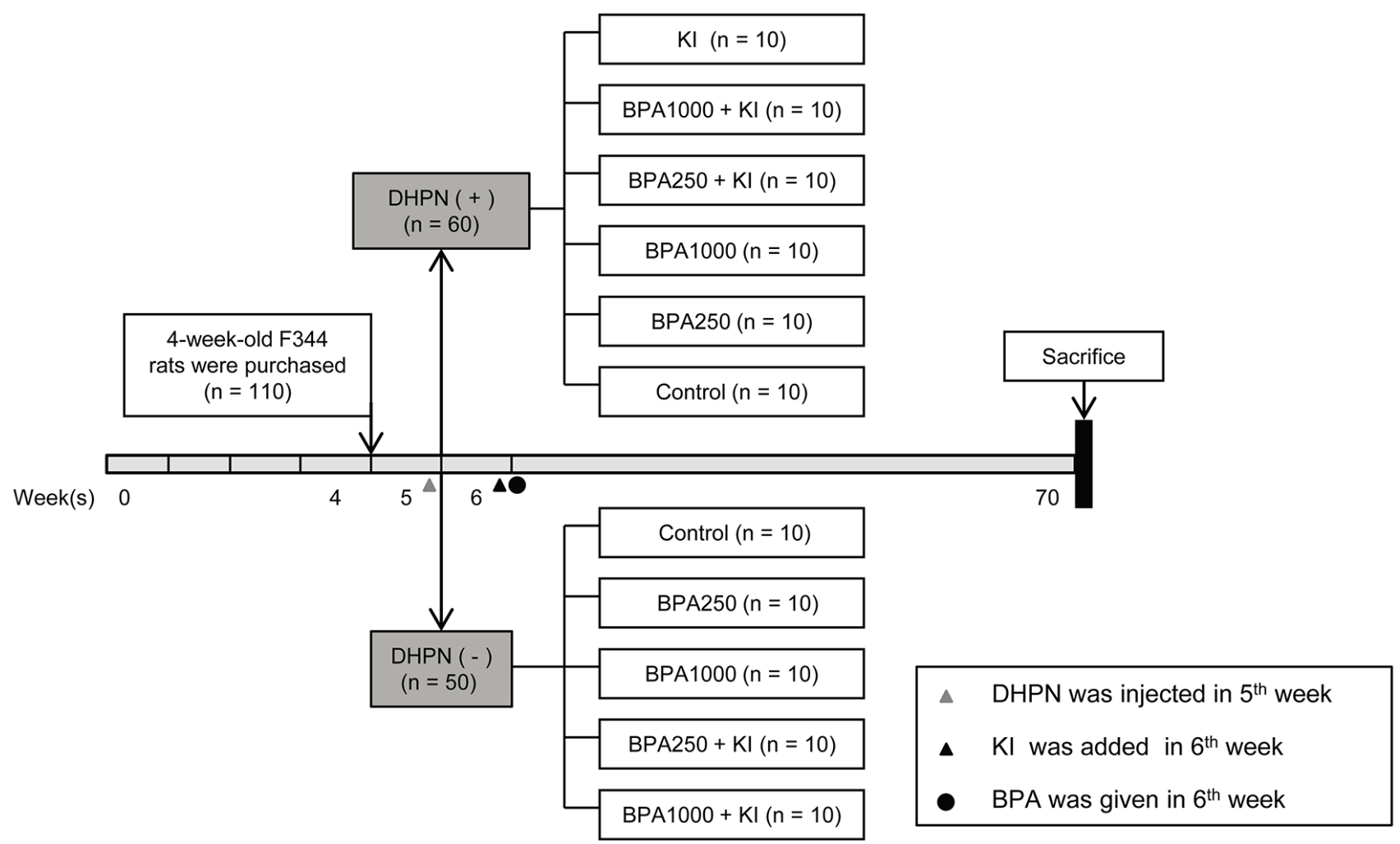

Figure 1: Schematic diagram of the experimental timeline. 1104 -week-old female F344 rats were acclimated and divided into a DHPN (+) group (DA group, $\mathrm{n}=60$ ) and a DHPN (-) group (DN group, $\mathrm{n}=50$ ). One week later, KI $1000 \mu \mathrm{g} / \mathrm{L}$ was added to the drinking water. Then according to different dosages of BPA, the DN group was randomly divided into 5 subgroups: the control group, the BPA250 group, the BPA1000 group, the BPA250 + KI group, and the BPA1000 + KI group. The DA group was divided into 6 subgroups containing the aforementioned 5 subgroups and an extra KI group. The rats were sacrificed after 64 weeks of exposure. 
apparent difference was found between BPA250 + KI and BPA1000 + KI, as seen in Figure 4B. The Western blotting detection in each group showed similar tendencies (Figure 4C and 4D).

\section{Effects of BPA on the expression of ERa}

In the DN groups, the immunochemistry score of $\mathrm{ER} \alpha$ in BPA1000 tended to be the highest, followed by BPA250 + KI and BPA1000 + KI, but no significance was found among all groups (Figure 4A). In the DA groups, the immunochemistry scores of ER $\alpha$ showed significant differences among all groups $(P<0.05)$. ER $\alpha$ expressions in the BPA1000, BPA250 + KI, and BPA1000 + KI groups were significantly higher than in the control group $(P<$ $0.05, P<0.01$, and $P<0.01$, respectively). In addition, ER $\alpha$ expression in KI was significantly lower than BPA250 $+\mathrm{KI}$ and BPA $1000+\mathrm{KI}(P<0.05 ; P<0.05)$ (Figure 4B).

Consistent with the increasing trend of ER $\alpha$ immunochemistry expression with the increasing dose of BPA, ER $\alpha$ protein expression also increased (Figure 4C and 4D). ER $\alpha$ protein expression in BPA250 and BPA1000
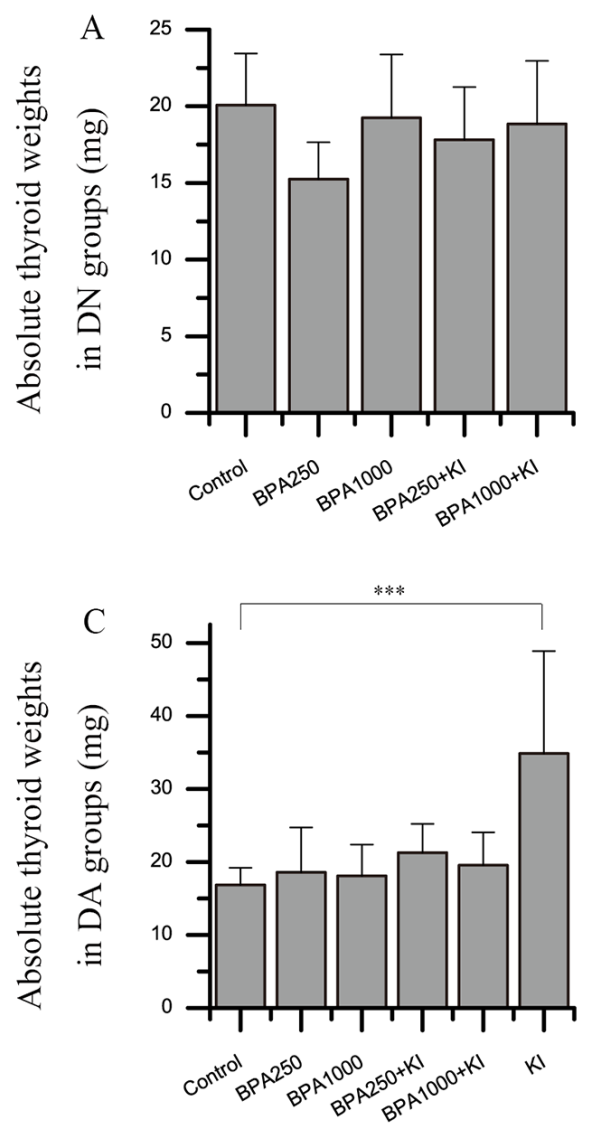

was apparently upregulated compared to the control group $(P<0.05 ; P<0.05)$, while no significance existed between the 2 dosages (Figure 5B).

\section{The relationship between ER $\alpha$ and PCNA expression}

\section{Expression of ERa was correlated to PCNA}

After excluding the influence of $\mathrm{KI}$ on PCNA expression, Spearman's correlation analysis of immunochemistry scores of ER $\alpha$ and PCNA was conducted in the control, BPA250, and BPA1000 of both the DN and DA groups. In the DN groups, the ER $\alpha$ expression was correlated to PCNA ( $\mathrm{r}=0.562 ; P<0.05 ; \mathrm{n}=20)$ (Figure $6 \mathrm{~A}(\mathrm{a}))$. Consistently, in the DA groups, the correlation between the ER $\alpha$ and PCNA scores was significantly positive $(\mathrm{r}=0.656 ; P<0.01 ; \mathrm{n}=18)$ (Figure $6 \mathrm{~A}(\mathrm{~b})$ ).

\section{Immunological location of $\mathrm{ER \alpha}$ was consistent with} PCNA

In the present thyroid samples, ER $\alpha$ and PCNA were expressed in both normal tissues and hyperplasia lesions.
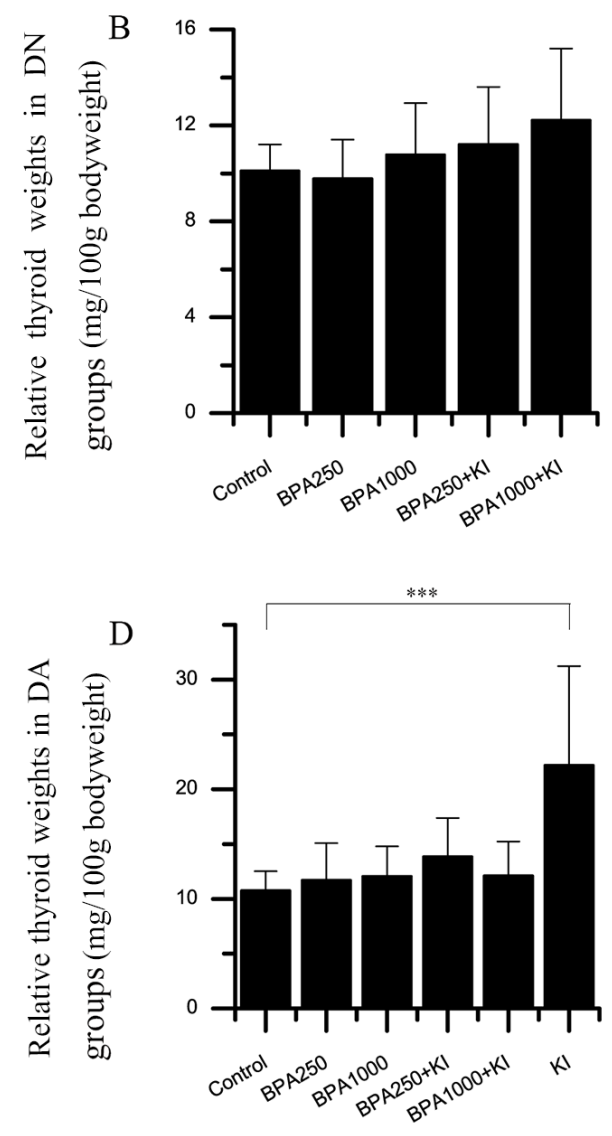

Figure 2: Effects of BPA and KI on the absolute and relative thyroid weights of rats. Three samples were excluded due to their abnormally heavy weights (respectively, $235.0 \mathrm{mg}$ in BPA250 + KI, $347.2 \mathrm{mg}$ and $148.7 \mathrm{mg}$ in BPA1000 + KI). (A) Absolute thyroid weights in the DN groups. (B) Relative thyroid weights in DN groups. The relative thyroid weights were in an increasing trend with the increased exposure dose of BPA and KI. (C) Absolute thyroid weights in the DA groups. (D) Relative thyroid weights in the DA groups. $\left({ }^{* * *} P<0.001\right)$. 
ER $\alpha$ was expressed mainly on the cell nucleus, with less on the cell membrane and cytoplasm. PCNA was located on the cell nucleus.

In normal thyroid tissues, ER $\alpha$ was distributed on small follicles composed of cuboidal or columnar epithelial cells with less colloid in the lumens, whose function was thought to be active rather than flattened epithelial cells with rich colloid in the lumens (Figure $6 \mathrm{C}(\mathrm{C})$ ) (it developed in all animals regardless of the exposure elements). Similarly, PCNA had a higher expression on the cuboidal and columnar epithelial cells compared to the surrounding flattened epithelial cells (Figure 6C(F)).

$\mathrm{ER} \alpha$ expression in the hyperplasia lesions was more higher than in the surrounding normal tissues, especially in the thyroid tumors (Figure 6C(A)) and complex papillary branches Figure 6C(B)) (regardless of the interventions). Consistently, the density and color depth of PCNA was more obvious in tumors (Figure 6C(D)) and focal hyperplasia lesions (Figure 6C(E)) than in the surrounding normal follicular cells, indicating an increased proliferative activity.

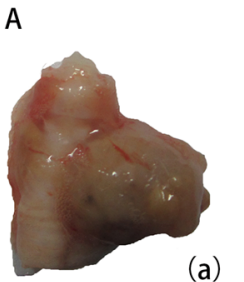

(a)

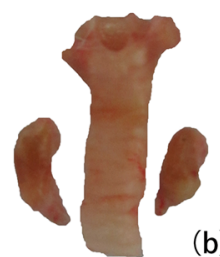

(b)

B
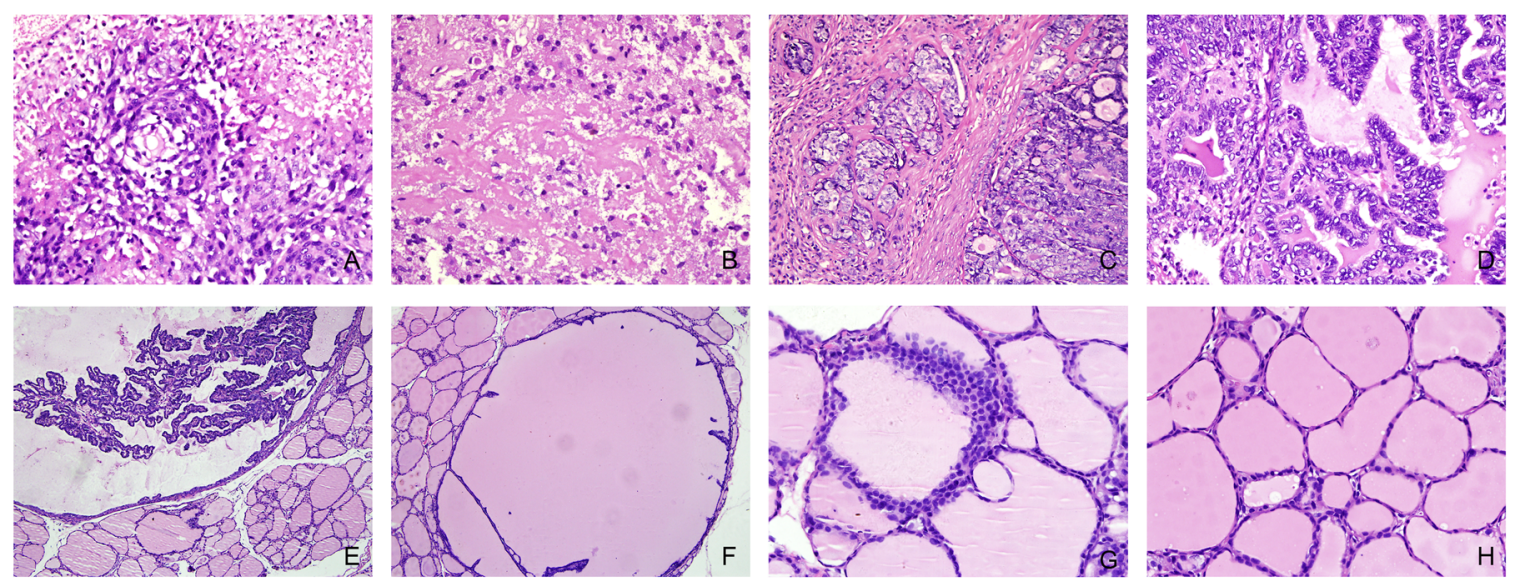

D

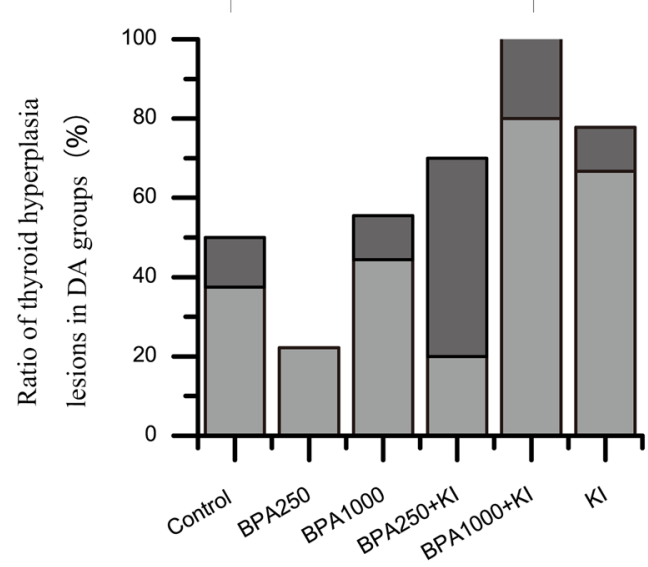

Figure 3: (A) Gross morphologies of the thyroid gland. (a): Typical PTC in BPA1000 + KI of the DA groups. (b): Thyroid hyperplasia in KI of the DA groups. (c): Normal thyroid in control of the DN groups. (B) Thyroid pathological structures under a microscope (H\&E). (A): ATC $(\times 400)(B)$ : MTC $(\times 400)$. (C): PTC with widely interstitial infiltration $(\times 200)$. (D): Classical PTC $(\times 400)$. (E): Atypical papillary hyperplasia $(\times 400)$. $(\mathrm{F})$ : Benign papillary hyperplasia $(\times 200)$. $(\mathrm{G})$ : C-cell proliferation $(\times 400)$. $(\mathrm{H})$ : Normal thyroid follicular follicles $(\times 400)$. (C) Ratio of thyroid hyperplasia lesions in the DN groups (including tumors and focal hyperplasia lesions). (D) Ratio of thyroid hyperplasia lesions in the DA groups. $\left({ }^{*} P<0.05\right)$. 


\section{$17-\beta$ estradiol $\left(E_{2}\right)$ had no influence on $E R \alpha$ immunochemistry scores}

In order to judge and exclude the influence of endogenous $E_{2}$ on $E R \alpha$ expression, serum $E_{2}$ levels were detected. The data was presented as the $\mathrm{X}$-axis of Spearman's correlation analysis between endogenous $\mathrm{E}_{2}$ and corresponding ER $\alpha$ expression, as is shown in Figure 6B. There was no significant correlation between $\mathrm{E}_{2}$ concentrations and corresponding ER $\alpha$ immunochemistry scores $(\mathrm{r}=-0.157, P=0.287, \mathrm{n}=48)$.

\section{Effects of BPA and KI on serum $\mathrm{FT}_{3}, \mathrm{FT}_{4}$, and TSH concentrations}

Serum TSH, $\mathrm{FT}_{3}$, and $\mathrm{FT}_{4}$ concentrations were examined to observe the effect of BPA and KI on thyroid function (Table 2).

In the DN groups, TSH in the control was the highest, with no apparent fluctuation happening among the other groups. With the increase of BPA doses, $\mathrm{FT}_{4}$ concentration showed a tendency to increase. $\mathrm{FT}_{4}$ in BPA1000 $(24.77 \pm 10.12 \mathrm{pmol} / \mathrm{L})$ was significantly higher than in the control $(17.99 \pm 2.70 \mathrm{pmol} / \mathrm{L}, P<0.05)$. In $\mathrm{BPA} 250+\mathrm{KI}$ and BPA1000 + KI of the DN groups,

A

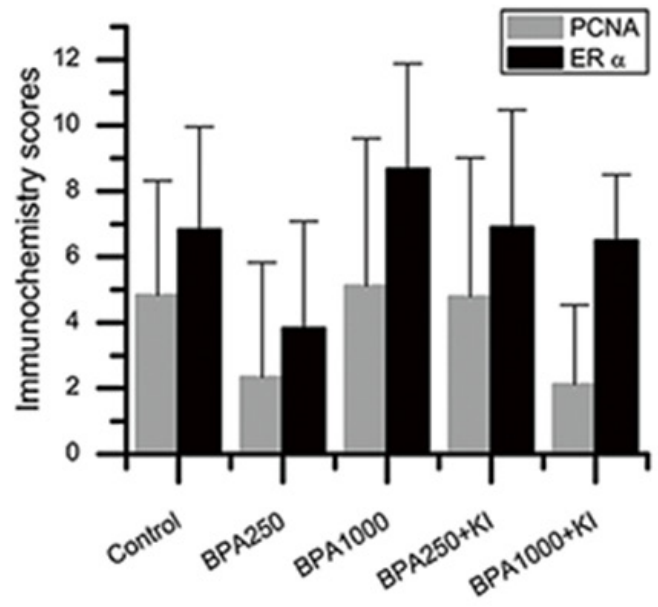

C

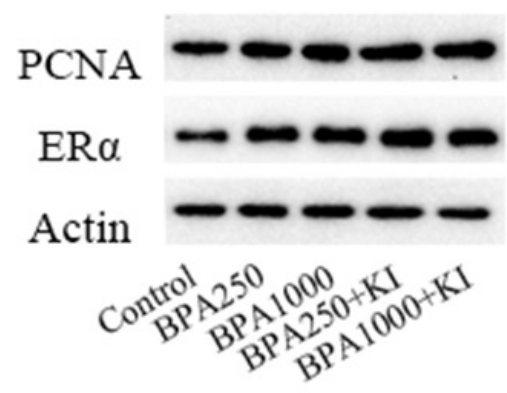

compared to the control, the $\mathrm{FT}_{3}$ and $\mathrm{FT}_{4}$ concentration had a tendency to increase with no statistical differences.

In the DA groups, TSH in KI was significantly higher than in the control $(P<0.05)$. The average $\mathrm{FT}_{4}$ concentration in BPA1000 was the highest $(23.87 \pm$ $3.94 \mathrm{pmol} / \mathrm{L}$ ). The $\mathrm{FT}_{3}$ and $\mathrm{FT}_{4}$ concentrations in BPA250 $+\mathrm{KI}$ and BPA1000 + KI were also higher than in the control, but no statistical differences were observed among the groups.

\section{DISCUSSION}

In the present study, TC models were developed using female F344 rats exposed to BPA for 64 weeks with/without the basic treatment of KI and DHPN. BPA increased the susceptibility to TC on the basis of DHPN and KI. BPA or KI alone could not directly increase TC incidence. The increased expression of ER $\alpha$ probably participated in the proliferation effect of BPA.

The carcinogenesis effect of KI in human studies has always been controversial, but it has been reported to promote TC in animal research. In a 2-stage carcinoma study, KI at a concentration of $260 \mathrm{mg} / \mathrm{L}$ promoted the genesis of TC in DHPN-treated F344 rats after 26 weeks of exposure [2]. Boltze et al [29] fed rats iodine 10-fold

B

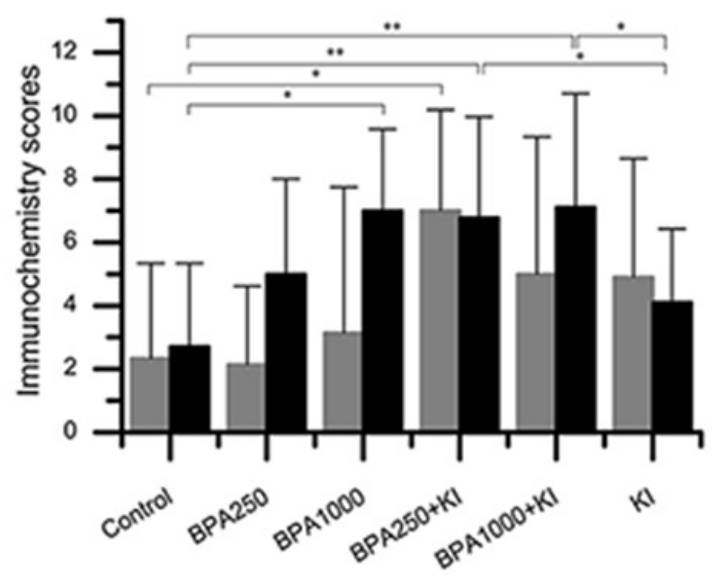

D

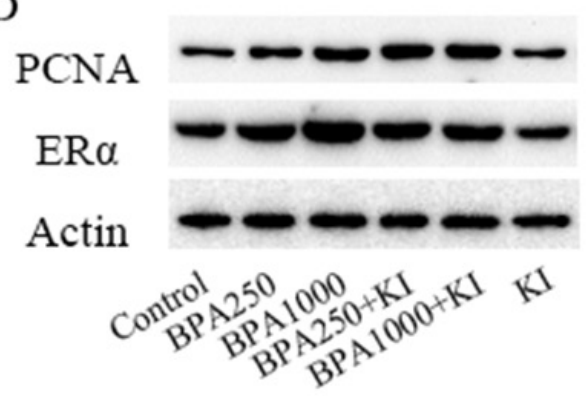

Figure 4: Immunochemistry and protein expression of ER $\alpha$ and PCNA in the rat thyroids. (A) Immunochemistry scores of ER $\alpha$ and PCNA in the DN groups. (B) Immunochemistry scores of ER $\alpha$ and PCNA in the DA groups. (C) Protein expression of ER $\alpha$ and PCNA in the DN groups. (D) Protein expression of ER $\alpha$ and PCNA in the DA groups. $\left({ }^{*} P<0.05\right.$; $\left.{ }^{* *} P<0.01\right)$. 
higher than controls for 110 weeks, and the thyrocyte proliferation rate and thyroid adenomas increased. Inconsistently, our results showed that 64 weeks of exposure to $1000 \mu \mathrm{g} / \mathrm{L} \mathrm{KI}$ failed to increase the obvious incidence of thyroid tumors. This may due to the shorter exposure time and smaller dosage compared to other studies. Although no obvious increase of TC incidence occurred, KI remarkably stimulated thyroid growth and proliferation. As shown, the thyroid weight in the KI group was the highest and the PCNA expression in the $\mathrm{KI}$ group increased more than in the control group. TSH is in particular an independent risk factor for thyroid tumors. The serum TSH level in the KI group in the present research was higher than in the control, which may directly contribute to thyroid proliferation [30].

As an endocrine disruptor, BPA could disturb biological functions and organ structures in extremely low concentrations. As was reported, $250 \mu \mathrm{g} / \mathrm{kg}$ BPA increased prevalence of intraductal hyperplasia in mammary of female rats at pup day 400 [31]. Except for the breast, BPA lower than $1000 \mu \mathrm{g} / \mathrm{kg}$ could induce benign and malignant hyperplasia lesions in the uterus and ovary of CD-1 mice [32]. In contrast to previous studies, our results showed that BPA $250 \mu \mathrm{g} / \mathrm{kg}$ or $1000 \mu \mathrm{g} / \mathrm{kg}$ alone did not apparently increase the incidence of thyroid tumors and focal hyperplasia lesions, although with the stimulation of DHPN. The thyroid weights also had no apparent changes. We reasoned that this inconsistency was probably due to different sensitivities of binding sites in different organs toward xenoestrogen. Besides, as the first to explore the influence of chronic exposure to low doses of BPA (lower than LOAEL) on thyroid proliferation, the present concentration might be not sufficient to induce pathological changes without other basic stimulus. Although there was no significant increase of tumors and focal hyperplasia lesions, the PCNA protein in the BPAexposed groups had a tendency to increase, indicating a potential proliferation effect on thyroid cells.

It is believed that the combination exposure of environmental disruptors with mutagens induces TCs. For example, 4 Gy radiation apparently induced thyroid tumors in F344 rats with the existence of 10-fold iodine intake [29]. Combined exposure to excess soybean and iodine deficiency promoted thyroid tumorigenesis in DHPN-initiated F344 rats [33]. In the present study, when BPA and KI are taken together, the incidence of PTC in BPA250 + KI of the DA groups reached the highest at $50 \%$, and the total incidence of thyroid hyperplasia lesions (including both tumors and focal hyperplasia lesions) in BPA $1000+\mathrm{KI}$ of the DA groups reached $100 \%$, including
A
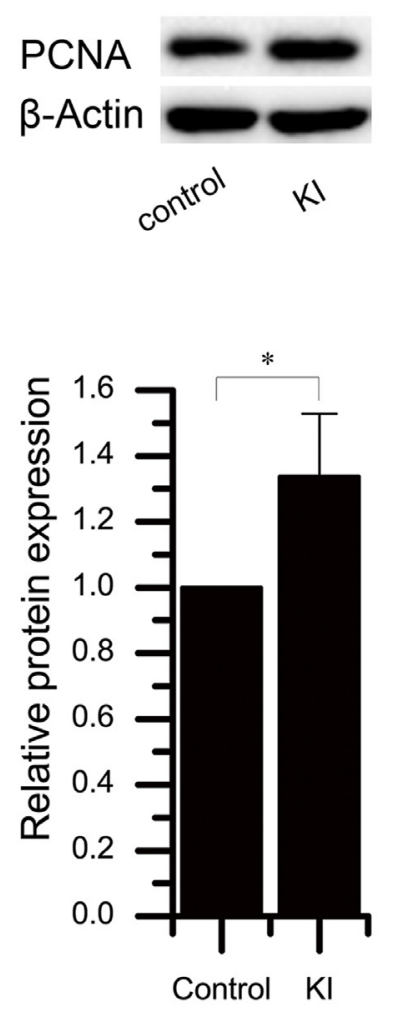

B
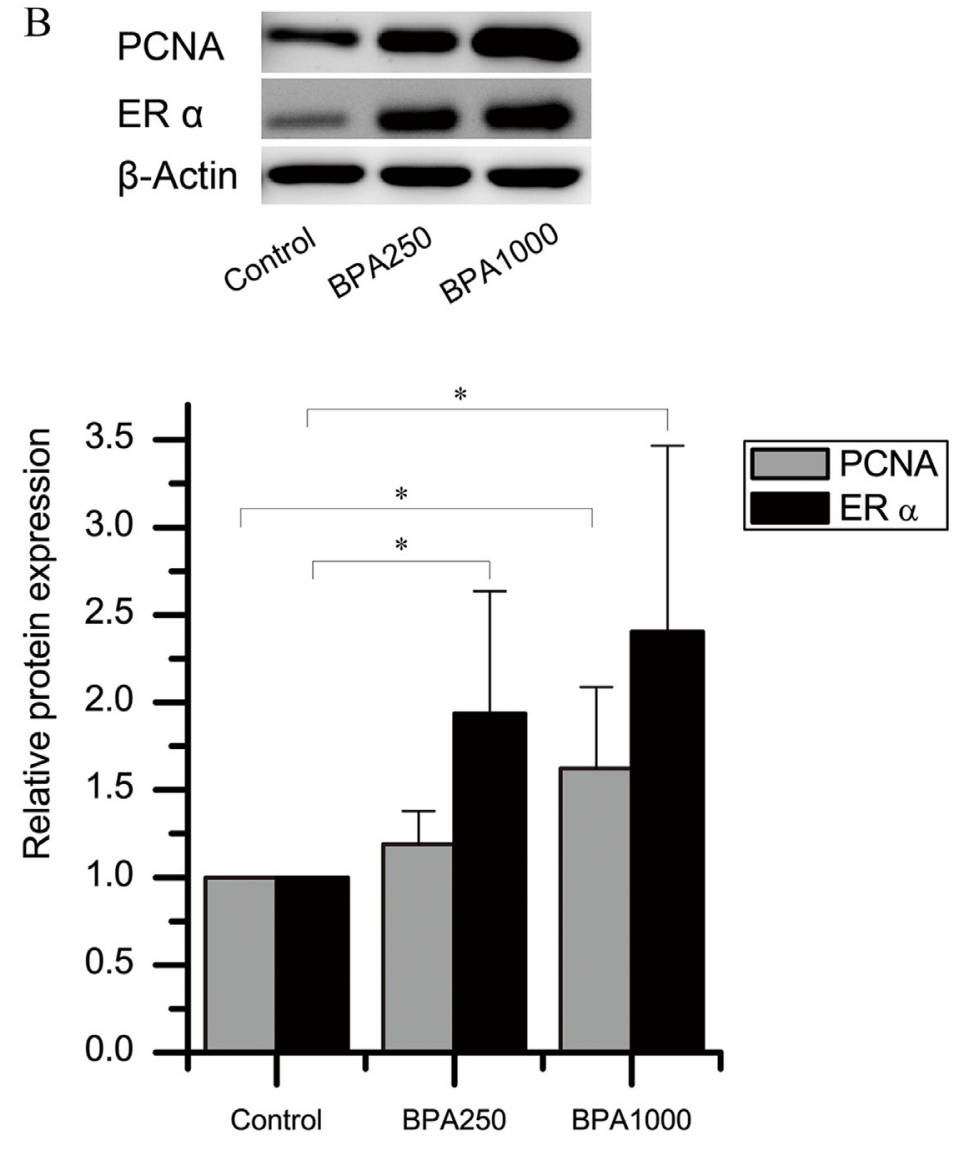

Figure 5: Protein expression of ER $\alpha$ and PCNA in the rat thyroids. (A) PCNA protein levels in KI and control of the DA group. (B) ER $\alpha$ and PCNA protein levels of BPA 250, BPA1000, and control of the DN groups. $\beta$-actin is the loading reference. $\left({ }^{*} P<0.05\right)$. 
A (a)

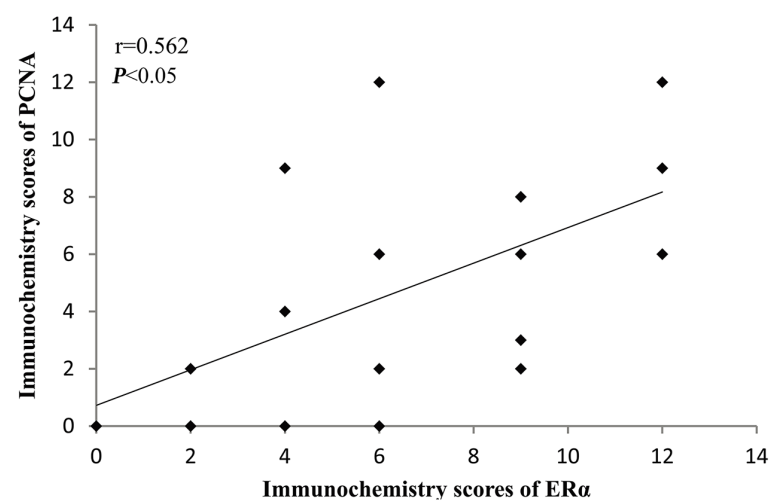

B

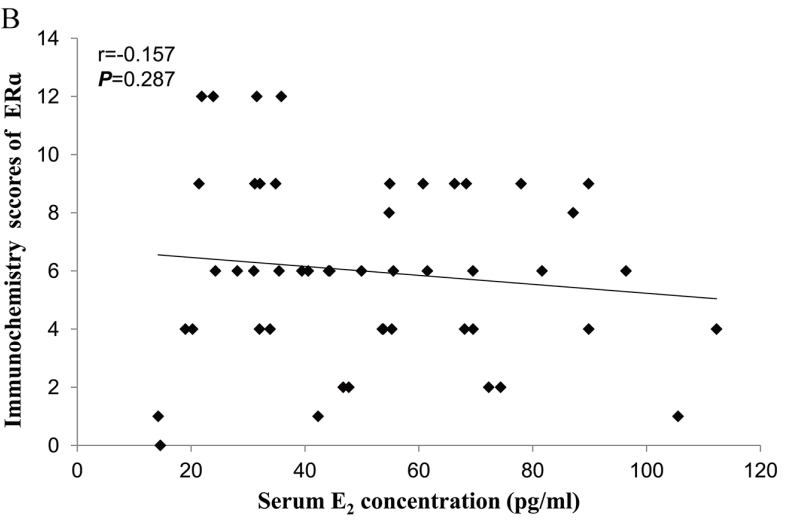

(b)

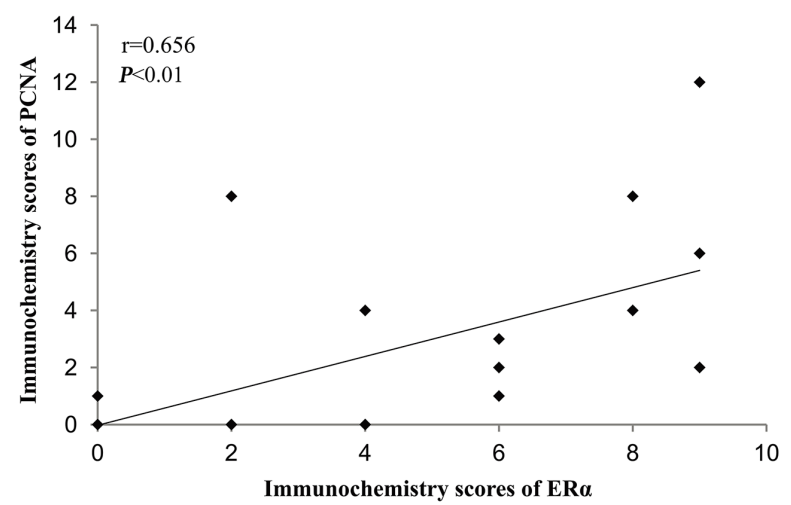

C
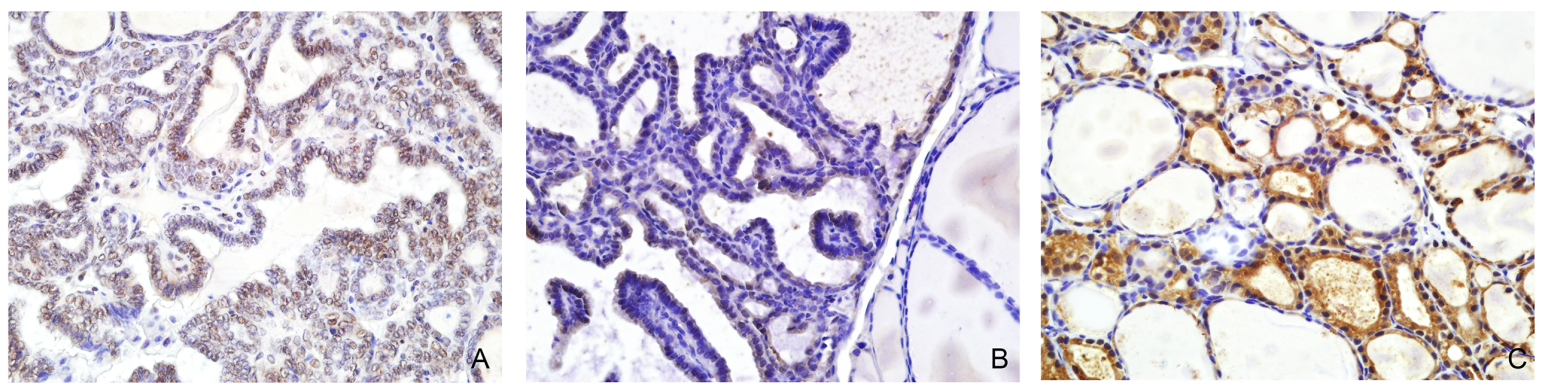

ER $\alpha$

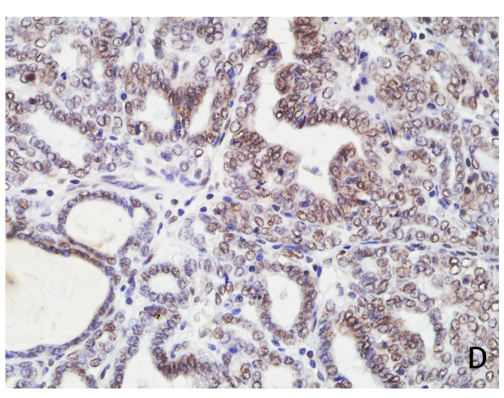

PTC

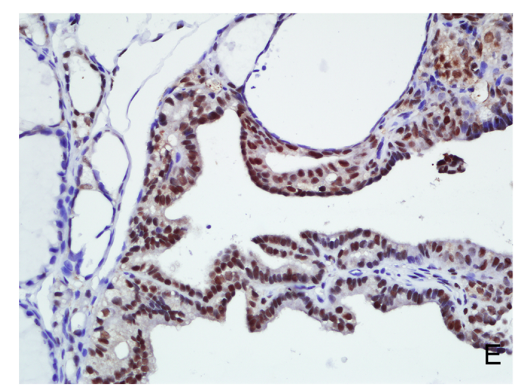

Focal thyroid hyperplasia

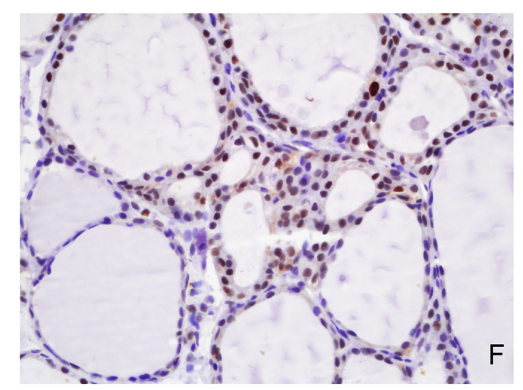

Normal thyroid follicular cells

Figure 6: (A) Spearman's correlation between the ER $\alpha$ and PCNA immunochemistry scores. (a): The correlation between ER $\alpha$ and PCNA in control, BPA250, and BPA1000 of the DN groups $(\mathrm{r}=0.562 ; P<0.05 ; \mathrm{n}=20)$. (b): The correlation between ER $\alpha$ and PCNA in control, BPA250, and BPA1000 of the DA groups $(\mathrm{r}=0.656 ; P<0.01 ; \mathrm{n}=18)(\mathrm{r}=$ Spearman's correlation coefficient). (B) Spearman's correlation between the serum $\mathrm{E}_{2}$ concentration and the $\mathrm{ER} \alpha$ immunochemistry scores $(\mathrm{r}=0.157 ; P>0.05 ; \mathrm{n}=48)$. (C) ER $\alpha$ and $\mathrm{PCNA}$ immunochemistry location in the rat thyroids. (IHC staining) $(\times 400)(\mathrm{A})$ : Positive expression of ER $\alpha$ on PTC cells. (B): Positive expression of ER $\alpha$ on a focal hyperplasia lesion, accompanied by negative expression in the surrounding normal cells. (C): Positive expression of ER $\alpha$ on cuboidal epithelial cells in normal thyroid tissue surrounded by flattened epithelial cells with negative ER $\alpha$ expression. (D): Positive expression of PCNA on PTC cells. (E): Positive expression of PCNA on a focal hyperplasia lesion with negative PCNA expression in the surrounding thyroid cells. (F): Positive expression of PCNA on cuboidal epithelial cells in normal thyroid tissue. 
precancerous lesions such as atypical papillary hyperplasia and C-cell proliferation. The result first proved that BPA could apparently promote thyroid carcinogenesis in the basic treatment of KI and DHPN in F344 rats.

Although BPA1000 + KI did not promote PTC, the malignant degrees of MTC and ATC were much higher than PTC. The results demonstrated that, on the basis of KI and DHPN, a lower concentration of BPA could increase the incidence of PTC while a higher concentration of BPA could elevate the malignancy degree of tumors. In toxicology studies, nonlinear dose-response curves between the biological activity and the concentration have been commonly reported, such as an "S"-shape or an inverted "U"-shape curve $[34,35]$. Therefore, we speculated that BPA250 $\mu \mathrm{g} / \mathrm{kg}$ was more effective in promoting PTC than BPA1000 $\mu \mathrm{g} / \mathrm{kg}$. Besides, DNA microarray studies in vitro reported that increasing doses of xenoestrogen resulted in entirely different arrays of genes, so there should be not only a quantitative change in end points as the dose increases. Instead, entirely different types of effects could occur [36, 37]. But this needs further research in vivo with a wider BPA concentration range.

In the present study, contrary to the KI group, the $\mathrm{FT}_{4}$ level in BPA1000 of the DN groups tended to increase while TSH had a mild decrease. Zoeller et al [38] also found a significant increase in $T_{4}$ levels in Sprague Dawley (SD) rats, which was in line with our results. In humans, a cross-sectional study with 3394 participants found that increased urinary BPA was related to elevated $\mathrm{FT}_{3}$ and decreased TSH concentrations [39]. Considering the decreased tendency of TSH and increased tendency of $\mathrm{FT}_{4}$ in BPA-treated groups compared to KI groups, we considered that BPA promotes thyroid hyperplasia lesions via other pathways rather than directly disturbing thyroid function.

ERs belong to the nuclear receptor family and mainly include 2 types: ER $\alpha$ and ER $\beta$. ER $\alpha$ is thought to be associated with the promotion of thyroid proliferation while ER $\beta$ plays an opposite role [40]. Nuclear ER $\alpha$ can directly bind to genes and induce downstream transcription, while membrane $\mathrm{ER} \alpha(\mathrm{mER} \alpha)$ can participate in the MAPK signaling pathway and the PI3K-AKT pathway so as to induce a proliferation effect $[41,42]$. Case-control studies show that ER $\alpha$ expression in PTC tissues is significantly higher than in normal tissues. Thyroid tumors with positive ER $\alpha$ have a larger size and higher prevalence of local metastasis $[19,43]$. ER $\beta$ downregulation was mainly associated with neck and lymph node metastasis and distant metastasis [44]. Furthermore, several studies found $E R \beta$ expression had no special significance in TC tissues. Therefore, we mainly focused on ER $\alpha$ to explore the proliferation effect induced by BPA.

ER $\alpha$ expression has always been tightly related to PCNA expression. Hao L et al [45] found PCNA and $\mathrm{ER} \alpha \mathrm{mRNA}$ expression level in pituitary of 12-week-old female F344 rats were both enhanced after BPA treatment. $\mathrm{ER} \alpha$ inhibitor ICI182 780 decreased ER $\alpha$ and PCNA mRNA levels in uteri of ovariectomized SD rats [46]. ER $\alpha$ also regulates cell cycle by upregulating PCNA and Ki-67 and suppressing p53/p21 to promote MCF-7 cell proliferation [47]. Consistently, in the present research, ER $\alpha$ expression and the immunochemistry location were positively correlated with PCNA expression. Besides, $\mathrm{E}_{2}$ levels had no correlation with ER $\alpha$ expression in the present research, which excluded the influence of internal $E_{2}$ concentration fluctuation on ER $\alpha$. So we concluded that the upregulation of $\mathrm{ER} \alpha$ in the thyroid probably participated in the proliferation process of BPA. Several studies also had similar findings. Xu et al [48] found that BPA could interfere with ER $\alpha$ signaling in the developing hippocampus in an ER-dependent manner. Neonatal BPA exposure disrupted meiosis progression during the first wave of spermatogenesis and increased the expression of $\mathrm{ER} \alpha$ and PCNA in the developing testes [49]. However, few studies have explored the possible mechanisms of how BPA increases ER $\alpha$ expression. Some research has speculated that BPA increases ER $\alpha$ expression via the $\mathrm{ER} \alpha$-mediated signaling pathway, since ER $\alpha$ antagonist ICI 182,780 could prevent $\mathrm{ER} \alpha$ upregulation in vitro experiments [46].

There are some limitations to this study. First, we did not perform extensive molecular research to explore the exact mechanism of how BPA acts on $\mathrm{ER} \alpha$ in vivo and in vitro. As a matter of fact, the main finding of our present study was to demonstrate the phenomenon that BPA exerts the ability to enhance the susceptibility of TC under the condition of DHPN and excess iodine. The exact molecular mechanism of how BPA can increase $\mathrm{ER} \alpha$ should be studied in future work. Second, we mainly performed a primary study to explore the potential role of $\mathrm{ER} \alpha$ on the pathogenesis of BPA-induced TC. However, there are also some other mechanisms that might participate in the carcinogenesis of TC, such as autophagy, apoptosis, cell proliferation, among others. Therefore, our study would be improved by measuring the expression of markers such as LC3, Beclin, Bax, and Bcl-2, to name a few.

In conclusion, in our research, a low dose of BPA could increase the susceptibility of TC on the basis of excess iodine and DHPN in F344 rats. BPA or KI alone could not induce an obvious increase of TC incidence. $\mathrm{ER} \alpha$ probably participates in the proliferation process.

\section{MATERIALS AND METHODS}

\section{Animals and treatments}

Specific-pathogen-free 4-week-old female Fischer 344 rats (F344 rats) obtained from Vital River China (Beijing, China) were housed 5 to a polypropylene cage with polypropylene plastic (PP) as bedding in an air- 
conditioned animal room (relative humidity $55 \pm 5 \%$, temperature $23 \pm 2{ }^{\circ} \mathrm{C}$, and ventilation 18 times $/ \mathrm{hr}$, with a 12-h light/dark cycle) and given a basal diet and tap water ad libitum. In order to avoid extra intake of BPA, the rearing cages, water bottles, and rat bedding were all made of PP that did not contain BPA. All experiments were performed following the protocols of the Animal Care and Use Committee of Shandong University.

Potassium iodide (KI, 99\% purity, Sigma-Aldrich, St. Louis, MO, USA) was dissolved in drinking water at a concentration of $1000 \mu \mathrm{g} / \mathrm{L}$ (the iodine concentration was calculated at $765 \mu \mathrm{g} / \mathrm{L})$. The iodine content in the feedstuff was approximately $500 \mu \mathrm{g} / \mathrm{kg}$ and in the drinking water was $10 \mu \mathrm{g} / \mathrm{L}$. The average food intake per rat was approximately $10 \mathrm{~g} /$ day and water consumption was $20 \mathrm{ml} /$ day. The average iodine intake per animal was calculated at $20.5 \mu \mathrm{g}$ /day in the KI groups and $5.2 \mu \mathrm{g} /$ day in the control groups.

BPA $(99 \%$ purity, Sigma-Aldrich, St. Louis, MO, USA) was dissolved in ethanol $(<0.01 \%)$ and administered by gavage at a daily dose of $250 \mu \mathrm{g} / \mathrm{kg}$ and $1000 \mu \mathrm{g} / \mathrm{kg}$ bodyweight, respectively, which was far lower than the LOAEL concentration of $50 \mathrm{mg} / \mathrm{kg} /$ day.

DHPN (Santai Labs, Inc., Jiangsu, China) was dissolved in saline as a vehicle and injected subcutaneously at a single dose of $2800 \mathrm{mg} / \mathrm{kg}$.

\section{Experimental design}

After 1 week of acclimatization, a total of 110 5-week-old rats were randomly divided into a DHPNinjected (DA) group $(\mathrm{n}=60)$ and a non-injected (DN) group $(\mathrm{n}=50)$. One week later, the $\mathrm{DN}$ group was randomly divided into 5 subgroups: a control group, a BPA $250 \mu \mathrm{g} / \mathrm{kg}$ (BPA250) group, a BPA1000 $\mu \mathrm{g} / \mathrm{kg}$ (BPA1000) group, a BPA $250 \mu \mathrm{g} / \mathrm{kg}+\mathrm{KI} 1000 \mu \mathrm{g} / \mathrm{L}$ (BPA250 + KI) group, and a BPA $1000 \mu \mathrm{g} / \mathrm{kg}+\mathrm{KI} 1000$ $\mu \mathrm{g} / \mathrm{L}$ (BPA $1000+\mathrm{KI}$ ) group, with 10 rats in each group. The DA group was divided into 6 subgroups, containing the aforementioned 5 subgroups and an extra subgroup: KI $1000 \mu \mathrm{g} / \mathrm{L}$ (KI) group, with 10 rats in each group. The rats were necropsied after 64 weeks of exposure (Figure 1). Their thyroids were dissected, weighed, and preserved for further histological examination, immunohistochemical staining, and Western blotting analysis. Serums were collected for hormone detection. Urine was collected for $24 \mathrm{~h}$ for iodine concentration detection.

\section{Urinary iodine detection}

Twenty-four $\mathrm{h}$ rat urine was collected into $5 \mathrm{ml}$ glass tubes and stored at $-20^{\circ} \mathrm{C}$. The urinary iodine concentration method was based on the Sandell-Kolthoff reaction after ammonium persulfate digestion, which was recommended in 2006 by the Ministry of Health of the People's Republic of China. The calibration curve ranged from 0 to $300 \mu \mathrm{g} / \mathrm{L}$.

\section{Histopathological examination}

The thyroids were fixed in $4 \%$ formaldehyde for 72 $\mathrm{h}$, then embedded in paraffin and sectioned into paraffin slides. The slides were deparaffinized, rehydrated, and rinsed in PBS. Then the slides were stained with hematoxylin and eosin, dehydrated, cleared in xylene, and mounted with coverslips. The number and types of hyperplasia lesions including thyroid tumors and focal hyperplasia lesions were examined under a microscope.

\section{Immunohistochemistry staining}

Immunohistochemical staining for ER $\alpha$ and PCNA was performed on all groups. Tissues sections were deparaffinized, rehydrated, and subjected to microwave antigen retrieval. Endogenous peroxidase was then blocked with $3 \% \mathrm{H}_{2} \mathrm{O}_{2}$. Nonspecific antibody binding was blocked with $5 \%$ goat serum. Then the sections were incubated with primary antibody at $4{ }^{\circ} \mathrm{C}$ overnight. Primary antibodies were respectively rabbit anti-PCNA $(1: 200)$ and rabbit antiER $\alpha$ (1:200) purchased from Abcam (Cambridge, MA, USA). The sections were incubated with the biotinylated secondary antibody for $1 \mathrm{~h}$ and washed in PBS. Color reactions were performed with $\mathrm{DAB}$. Then the sections were counterstained with hematoxylin, dehydrated, cleared in xylene, and mounted with coverslips. Negative control sections were incubated with PBS. According to the intensity of the dye color and the number of positive cells, the scores of specimens were calculated.

\section{Western blotting detection}

Western blotting analysis for ER $\alpha$ and PCNA was performed on all groups. The total protein was extracted, mixed with $5 \times$ SDS-PAGE sample buffer at a 4:1 ratio, and denatured by heating the sample to $99^{\circ} \mathrm{C}$ for $10 \mathrm{~min}$. After electrophoresis on SDS-PAGE, the proteins were separated. Then the target proteins were transferred to signed polyvinylidene difluoride (PVDF) membrane (Millipore, Bedford, MA, USA). After incubation with $5 \%$ skim milk, the membranes were incubated with primary antibody for $18 \mathrm{~h}$ at $4^{\circ} \mathrm{C}$. The primary antibodies for target proteins were respectively rabbit anti-ER $\alpha$ (1:150) and anti-PCNA (1:200) obtained from Abcam. Then the membranes were incubated with horseradish peroxidase conjugated secondary antibody for $1 \mathrm{~h}$ at room temperature with agitation. Bands were detected using the FluorChem E system (Bio-Techne, San Jose, CA, USA). The data were expressed as the relative net intensity of the target protein/ $\beta$-actin (ZSBIO, Beijing, China). At least 3 independent biological replicates were performed.

\section{Hormone detection}

$\mathrm{FT}_{3}$ and $\mathrm{FT}_{4}$ were detected using an automated chemiluminescence immunoassay analyzer (ADVIA 
Centaur XP). The normal range of $\mathrm{FT}_{3}$ was $2.3-6.3 \mathrm{pmol} / \mathrm{L}$ and $\mathrm{FT}_{4}$ was $10.3-24.5 \mathrm{pmol} / \mathrm{L}$. The serum TSH level was determined using a TSH ELISA kit (CUSABIO, Wuhan, China) based on the quantitative sandwich enzyme immunoassay technique, with a detection range of 0.6 $\mu \mathrm{IU} / \mathrm{ml}-24 \mu \mathrm{IU} / \mathrm{ml}$. The level of $\mathrm{E}_{2}$ was detected via an $\mathrm{E}_{2}$ ELISA kit (R\&D Systems, Inc., Minneapolis, MN, USA), which is based on the competitive binding technique. The assay range was $12.30-3,000 \mathrm{pg} / \mathrm{ml}$. Steps were performed according to the manufacturer's instructions.

\section{Statistical analysis}

All data and statistical significance were determined using SPSS statistic software (version 19.0, Chicago, IL, USA). Quantitative data were expressed as mean \pm SD. The normality test and the homogeneity of variance test were applied. One-way ANOVA and the LSD test were used to determine differences among the groups. When the variance analysis conditions did not agree, the KruskalWallis test was used. Qualitative data were analyzed using Fisher's exact test. In addition, Student's t-test was applied to determine urine concentration differences. Spearman's correlation analysis was applied between $\mathrm{ER} \alpha$ and PCNA immunochemistry scores, and between serum $\mathrm{E}_{2}$ concentration and $\mathrm{ER} \alpha$ immunochemistry scores. Differences were considered statistically significant at $P$ $<0.05$.

\section{Abbreviations}

BPA: Bisphenol A; DHPN: N-Bis (2-hydroxypropyl) nitrosamine; ER: estrogen receptor; KI: potassium iodine; MUI: median urinary iodine; PCNA: proliferating cell nuclear antigen; PTC: papillary thyroid carcinoma; TC: thyroid carcinoma; UIC: urinary iodine concentration.

\section{Author contributions}

Ling Jiang, Yanan Li, Xiaochen Zhang and Jing Zhang designed the research; Jing Zhang, Xiaochen Zhang, Zhenzhen Zhou, Lanxiang Hao, Shanshan Fan, Yan Xie and Fang Jiang carried out the experiments; Xiaochen Zhang, Jing Zhang, Chuanlong Wu and Zhiyan Liu analyzed the data; Jing Zhang, Xiaochen Zhang and Ling Jiang wrote and revised the paper.

\section{ACKNOWLEDGMENTS}

This work was supported by the National Natural Science Foundation of China (No. 81272181) and the Science and Technology Development Project of Shandong Province (No. 2012GSF11851).

\section{CONFLICTS OF INTEREST}

The authors declare no competing financial interest.

\section{REFERENCES}

1. Zimmermann MB, Galetti V. Iodine intake as a risk factor for thyroid cancer: a comprehensive review of animal and human studies. Thyroid Res. 2015; 8:8.

2. Kanno J, Onodera H, Furuta K, Maekawa A, Kasuga T, Hayashi Y. Tumor-promoting effects of both iodine deficiency and iodine excess in the rat thyroid. Toxicol Pathol. 1992; 20:226-235.

3. de Vathaire F, Haddy N, Allodji R, Hawkins M, Guibout C, El-Fayech C, Teinturier C, Oberlin O, Pacquement H, Diop F, Kalhouche A, Benadjaoud M, Winter D, et al. Thyroid radiation dose and other risk factors of thyroid carcinoma following childhood cancer. J Clin Endocrinol Metab. 2015; 100:4282-4290.

4. Vigneri R, Malandrino P, Giani F, Russo M, Vigneri P. Heavy metals in the volcanic environment and thyroid cancer. Mol Cell Endocrinol. 2016.

5. Liu S, Gao A, Zhang B, Zhang Z, Zhao Y, Chen P, Ji M, Hou P, Shi B. Assessment of molecular testing in fineneedle aspiration biopsy samples: an experience in a Chinese population. Exp Mol Pathol. 2014; 97:292-297.

6. Teng W, Shan Z, Teng X, Guan H, Li Y, Teng D, Jin Y, Yu X, Fan C, Chong W, Yang F, Dai H, Yu Y, et al. Effect of iodine intake on thyroid diseases in China. N Engl J Med. 2006; 354:2783-2793.

7. Yasuhara K, Koujitani T, Takegawa K, Nasu M, Onodera H, Takagi H, Hirose M, Mitsumori K. Promoting effects of xylazine on development of thyroid tumors in rats initiated with N-bis(2-hydroxypropyl)nitrosamine and the mechanism of action. Carcinogenesis. 2001; 22:613-618.

8. Zimmermann MB, Andersson M. Assessment of iodine nutrition in populations: past, present, and future. Nutr Rev. 2012; 70:553-570.

9. Wang F, Wang Y, Wang L, Wang X, Sun C, Xing M, Zhao W. Strong association of high urinary iodine with thyroid nodule and papillary thyroid cancer. Tumour Biol. 2014; 35:11375-11379.

10. Franceschi S. Iodine intake and thyroid carcinoma--a potential risk factor. Exp Clin Endocrinol Diabet. 1998; 106:S38-44.

11. Kolonel LN, Hankin JH, Wilkens LR, Fukunaga FH, Hinds MW. An epidemiologic study of thyroid cancer in Hawaii. Cancer Causes Control. 1990; 1:223-234.

12. Yafune A, Taniai E, Morita R, Akane H, Kimura M, Mitsumori K, Shibutani M. Immunohistochemical cellular distribution of proteins related to $\mathrm{M}$ phase regulation in early proliferative lesions induced by tumor promotion in rat two-stage carcinogenesis models. Exp Toxicol pathol. 2014; 66:1-11.

13. Takegawa K, Mitsumori K, Onodera H, Shimo T, Kitaura K, Yasuhara K, Hirose M, Takahashi M. Studies on the carcinogenicity of potassium iodide in F344 rats. Food Chem Toxicol. 2000; 38:773-781. 
14. Zahid M, Goldner W, Beseler CL, Rogan EG, Cavalieri EL. Unbalanced estrogen metabolism in thyroid cancer. Int $\mathrm{J}$ Cancer. 2013; 133:2642-2649.

15. Derwahl M, Nicula D. Estrogen and its role in thyroid cancer. Endocr Relat Cancer. 2014; 21:T273-283.

16. Joseph KR, Edirimanne S, Eslick GD. The association between breast cancer and thyroid cancer: a metaanalysis. Breast Cancer Res. 2015; 152:173-181.

17. Tang W, Liu R, Yan Y, Pan X, Wang M, Han X, Ren H, Zhang Z. Expression of estrogen receptors and androgen receptor and their clinical significance in gastric cancer. Oncotarget. 2017; 8:40765-40777. doi: 10.18632/oncotarget.16582.

18. Batmunkh B, Choijookhuu N, Srisowanna N, Byambatsogt U, Synn Oo P, Noor Ali M, Yamaguchi Y, Hishikawa Y. Estrogen accelerates cell proliferation through estrogen receptor alpha during rat liver regeneration after partial hepatectomy. Acta Histochem Cytochem. 2017; 50:39-48.

19. Chen D, Qi W, Zhang P, Guan H, Wang L. Expression of the estrogen receptor alpha, progesterone receptor and epidermal growth factor receptor in papillary thyroid carcinoma tissues. Oncol Lett. 2015; 10:317-320.

20. An JH, Hwangbo Y, Ahn HY, Keam B, Lee KE, Han W, Park do J, Park IA, Noh DY, Youn YK, Cho BY, Im SA, Park YJ. A possible association between thyroid cancer and breast cancer. Thyroid. 2015; 25:1330-1338.

21. Paulose T, Speroni L, Sonnenschein C, Soto AM. Estrogens in the wrong place at the wrong time: Fetal BPA exposure and mammary cancer. Reprod Toxicol. 2015; 54:58-65.

22. Healy BF, English KR, Jagals P, Sly PD. Bisphenol A exposure pathways in early childhood: reviewing the need for improved risk assessment models. J Exp Sci Environ Epidemiol. 2015; 25:544-556.

23. Derouiche S, Warnier M, Mariot P, Gosset P, Mauroy B, Bonnal JL, Slomianny C, Delcourt P, Prevarskaya N, Roudbaraki M. Bisphenol A stimulates human prostate cancer cell migration via remodelling of calcium signalling. Springerplus. 2013; 2:54.

24. Castro B, Sanchez P, Torres JM, Preda O, del Moral RG, Ortega E. Bisphenol A exposure during adulthood alters expression of aromatase and 5alpha-reductase isozymes in rat prostate. PLoS One. 2013; 8:e55905.

25. Doerge DR, Twaddle NC, Vanlandingham M, Brown RP, Fisher JW. Distribution of bisphenol A into tissues of adult, neonatal, and fetal Sprague-Dawley rats. Toxicol Appl Pharmacol. 2011; 255:261-270.

26. Acevedo N, Davis B, Schaeberle CM, Sonnenschein C, Soto AM. Perinatally administered bisphenol a as a potential mammary gland carcinogen in rats. Environ Health Perspect. 2013; 121:1040-1046.

27. Menard S, Guzylack-Piriou L, Lencina C, Leveque M, Naturel M, Sekkal S, Harkat C, Gaultier E, Olier M, GarciaVillar R, Theodorou V, Houdeau E. Perinatal exposure to a low dose of bisphenol A impaired systemic cellular immune response and predisposes young rats to intestinal parasitic infection. PLoS one. 2014; 9:e112752.

28. Jedeon K, Loiodice S, Marciano C, Vinel A, Canivenc Lavier MC, Berdal A, Babajko S. Estrogen and bisphenol A affect male rat enamel formation and promote ameloblast proliferation. Endocrinology. 2014; 155:3365-3375.

29. Boltze C, Brabant G, Dralle H, Gerlach R, Roessner A, Hoang-Vu C. Radiation-induced thyroid carcinogenesis as a function of time and dietary iodine supply: an in vivo model of tumorigenesis in the rat. Endocrinology. 2002; 143:2584-2592.

30. Ozemir IA, Gurbuz B, Bayraktar B, Aslan S, Baskent A, Yalman H, Yigitbasi R, Alimoglu O. The effect of thyroidstimulating hormone on tumor size in differentiated thyroid carcinoma. Indian J Surg. 2015; 77:967-970.

31. Mandrup K, Boberg J, Isling LK, Christiansen S, Hass U. Low-dose effects of bisphenol A on mammary gland development in rats. Andrology. 2016; 4:673-683.

32. Newbold RR, Jefferson WN, Padilla-Banks E. Prenatal exposure to bisphenol a at environmentally relevant doses adversely affects the murine female reproductive tract later in life. Environ Health Perspect. 2009; 117:879-885.

33. Nishikawa A, Ikeda T, Son HY, Okazaki K, Imazawa T, Umemura T, Kimura S, Hirose M. Pronounced synergistic promotion of N-bis(2-hydroxypropyl)nitrosamine-initiated thyroid tumorigenesis in rats treated with excess soybean and iodine-deficient diets. Toxicol Sci. 2005; 86:258-263.

34. Gao X, Ma J, Chen Y, Wang HS. Rapid responses and mechanism of action for low-dose bisphenol $\mathrm{S}$ on ex vivo rat hearts and isolated myocytes: evidence of femalespecific proarrhythmic effects. Environ Health Perspect. 2015; 123:571-578.

35. Peluso ME, Munnia A, Ceppi M. Bisphenol-A exposures and behavioural aberrations: median and linear spline and meta-regression analyses of 12 toxicity studies in rodents. Toxicology. 2014; 325:200-208.

36. Shioda T, Chesnes J, Coser KR, Zou L, Hur J, Dean KL, Sonnenschein C, Soto AM, Isselbacher KJ. Importance of dosage standardization for interpreting transcriptomal signature profiles: evidence from studies of xenoestrogens. Proc Natl Acad Sci U S A. 2006; 103:12033-12038.

37. Coser KR, Chesnes J, Hur J, Ray S, Isselbacher KJ, Shioda T. Global analysis of ligand sensitivity of estrogen inducible and suppressible genes in MCF7/BUS breast cancer cells by DNA microarray. Proc Natl Acad Sci U S A. 2003; 100:13994-13999.

38. Zoeller RT, Bansal R, Parris C. Bisphenol-A, an environmental contaminant that acts as a thyroid hormone receptor antagonist in vitro, increases serum thyroxine, and alters $\mathrm{RC} 3 /$ neurogranin expression in the developing rat brain. Endocrinology. 2005; 146:607-612.

39. Wang T, Lu J, Xu M, Xu Y, Li M, Liu Y, Tian X, Chen Y, Dai M, Wang W, Lai S, Bi Y, Ning G. Urinary bisphenol 
a concentration and thyroid function in Chinese adults. Epidemiology. 2013; 24:295-302.

40. Chen GG, Vlantis AC, Zeng Q, van Hasselt CA. Regulation of cell growth by estrogen signaling and potential targets in thyroid cancer. Curr Cancer Drug Targets. 2008; 8:367-377.

41. Thomas P. Role of G-protein-coupled estrogen receptor (GPER/GPR30) in maintenance of meiotic arrest in fish oocytes. J Steroid Biochem Mol Biol. 2017; 167:153-161.

42. Song X, Wei Z, Shaikh ZA. Requirement of ERalpha and basal activities of EGFR and Src kinase in Cd-induced activation of MAPK/ERK pathway in human breast cancer MCF-7 cells. Toxicol Appl Pharmacol. 2015; 287:26-34.

43. Di Vito M, De Santis E, Perrone GA, Mari E, Giordano MC, De Antoni E, Coppola L, Fadda G, Tafani M, Carpi A, Russo MA. Overexpression of estrogen receptor-alpha in human papillary thyroid carcinomas studied by lasercapture microdissection and molecular biology. Cancer Sci. 2011; 102:1921-1927.

44. Cheng S, Serra S, Mercado M, Ezzat S, Asa SL. A highthroughput proteomic approach provides distinct signatures for thyroid cancer behavior. Clin Cancer Res. 2011; $17: 2385-2394$.
45. Hao L, Zhang J, Zhang Y, Hu H, Shao W, Zhang X, Geng C, Wang Y, Jiang L. Effect of bisphenol a on occurrence and progression of prolactinoma and its underlying mechanisms. Am J Transl Res. 2016; 8:4195-4204.

46. Stygar D, Muravitskaya N, Eriksson B, Eriksson H, Sahlin L. Effects of SERM (selective estrogen receptor modulator) treatment on growth and proliferation in the rat uterus. Reprod Biol Endocrinol. 2003; 1:40.

47. Liao XH, Lu DL, Wang N, Liu LY, Wang Y, Li YQ, Yan TB, Sun XG, Hu P, Zhang TC. Estrogen receptor alpha mediates proliferation of breast cancer MCF-7 cells via a p21/PCNA/E2F1-dependent pathway. FEBS J. 2014; 281:927-942.

48. Xu XB, He Y, Song C, Ke X, Fan SJ, Peng WJ, Tan R, Kawata M, Matsuda K, Pan BX, Kato N. Bisphenol A regulates the estrogen receptor alpha signaling in developing hippocampus of male rats through estrogen receptor. Hippocampus. 2014; 24:1570-1580.

49. Xie M, Bu P, Li F, Lan S, Wu H, Yuan L, Wang Y. Neonatal bisphenol a exposure induces meiotic arrest and apoptosis of spermatogenic cells. Oncotarget. 2016; 7:10606-10615. doi: 10.18632/oncotarget.7218. 